\title{
Aspiration pneumonia in patients underwent head and neck surgery. A case series
}

\author{
La neumonía por aspiración en pacientes sometidos \\ a cirugía de cabeza y cuello. Una serie de casos
}

\author{
Yolanda Baca Morilla ${ }^{1}$; Paolo Cariati²; Almudena Cabello Serrano ${ }^{3}$; Fernando Monsalve \\ Iglesias ${ }^{2}$; Dario Sanchez Lopez ${ }^{3}$ \\ ${ }^{1}$ Anesthesiologist. Hospital Universitario Virgen de las Nieves, Granada (Spain) \\ ${ }^{2}$ Maxillofacial surgery resident. Hospital Universitario Virgen de las Nieves, Granada (Spain) \\ ${ }^{3}$ Maxillofacial surgeon. Hospital Universitario Virgen de las Nieves, Granada (Spain)
}

\begin{abstract}
Abstrasct
Patients underwent head and neck surgery might present numerous respiratory and gastrointestinal complications. The need to administrate enteral nutrition for long time periods promotes the emergence of such problems. In this line, is important to underline that these complications could be life threatening for the patients. The main aim of the present report is to examine the importance of performing a radiographic control after a NG tubes placement. We firmly believe that it represent the most reliable method to avoid respiratory complications related with NG tubes in high risk patients.

\section{Resumen}

Los pacientes sometidos a cirugía de cabeza y cuello pueden presentar numerosas complicaciones respiratorias y gastrointestinales. La necesidad de administrar la nutrición enteral durante largos períodos de tiempo promueve la aparición de tales problemas. En esta línea, es importante subrayar que estas complicaciones podrían poner en peligro la vida de los pacientes. El objetivo principal del presente informe es examinar la importancia de realizar un control radiográfico después de una colocación de tubos NG. Creemos firmemente que representa el método más fiable para evitar las complicaciones respiratorias relacionadas con los tubos NG en pacientes de alto riesgo.
\end{abstract}

Keywords: Head and neck surgery, Aspiration pneumonia, NG tubes complications, Radiographic control

\section{INTRODUCTION}

Patients underwent head and neck surgery might present numerous hassles during the immediate postoperative period (1). Respiratory and gastrointestinal complications are undoubtedly the most frequent among these (2). In fact, due to the surgical aggression of the upper aero-digestive path is mandatory to adopt measures of artificial nutrition. Thus, the placement of a NG tube is almost always required in these patient and it appropriate positioning is crucial. Life-threatening complication might be provoked by the misplaced of the nasogastric tube in the respiratory tract (3). In the light of the above, the aim of the present report is twofold. First, we examine the importance of performing a radiographic control after a NG tube placement in order to reduce the frequency of these complications. Second, we describe this syndrome with the goal of proposing effective preventive measures.

\section{MATERIAL AND METHODS AND RESULTS}

Patient 1: 29-year-old man underwent surgical drainage of a neck abscess (dental origin). A cervical approach was used to reach the submandibular space. A NG tube was placed due to swallowing problems experienced by patient during postoperative period. Three days after the NG tube placement, patient began to present refractory hypoxemia, tachypnea, fever and leukocytosis. In view of these findings, we decided to perform a chest x-ray. This test show the presence of a possible pneumonia. Finally a chest CT confirmed this diagnosis. Against this backdrop, enteral tube nutrition was stopped. Moreover, empirical antibiotic treatment was immediately administered. Fortunately, the patient evolved favorably and was discharged from intensive care unit 2 weeks later.
ACTUALIDAD M É D I C A www.actualidadmedica.es (0)2017.Actual.Med. Todoslos derechosresenvados
Paolo Cariati

Maxillofacial surgery resident.

Hospital Universitario Virgen de las Nieves, Granada (Spain)

E-mail: paolocariati@gmail.com 
Patient 2: A 36-year-old man underwent surgical drainage of a neck abscess (dental origin). A cervical approach was used to reach the submandibular space. A NG tube was placed immediately following surgery. Three days after, patient showed fever and leukocytosis. In light of the above, we decided to perform a chest $\mathrm{x}$-ray. This test evidenced a bilateral aspiration pneumonia. Promptly, the enteral tube nutrition was stopped and an empirical antibiotic treatment was administered. Importantly, this patient evolved favorably too and was discharged from intensive care unit 17 days later.

Patient 3: A 61-year-old man underwent major head and neck surgery. In fact, patient was diagnosed with squamous cell carcinoma. A NG tube was placed just after the surgery. Four days after, patient showed fever, refractory hypoxemia and leukocytosis. In view of that, a chest x-ray was carried out. This test evidenced a bilateral aspiration pneumonia. Once again, the enteral tube nutrition was stopped and an empirical antibiotic treatment was administered. The patient evolved favorably and was discharged from hospital 61 days later.

Patient 4: A 63-year-old man underwent major head and neck surgery. Patient was affected by squamous cell carcinoma of the tongue and floor of the mouth. Due to the extension of tumorectomy a pectoral flap was used for reconstructing the oncological defect of the oral cavity. Inmediately after surgery, a NG tube was placed in order to guarantee an adequate nutritional status of the patient. Six days after, patient presented fever, refractory hypoxemia and leukocytosis associated with signs and symptoms of sepsis. Considering all of this, we performed a chest $x$-ray. This test evidenced a lobular aspiration pneumonia. As before, the enteral tube nutrition was stopped and an empirical antibiotic treatment was administered. This patient evolved favorably too and was discharged from hospital 43 days later.

\section{DISCUSSION}

Nasogastric (NG) tubes are essential for patients who present swallowing problems. In fact, this tool ensures sufficient nutrition to meet daily patient requirements (4). In addition several drugs might also be administered through this way (5). However, several complications may be associated with the presence of NG tubes. Increase in gastric residue, constipation, diarrhea, abdominal distention and regurgitation of food represent some possible gastrointestinal complications of NG tube (6). On the other hand, death or severe harm might be provoked by the misplaced of the nasogastric tube in the respiratory tract (7). In this line, serious aspiration pneumonia or sever acute respiratory distress syndrome might be triggered by contact of the enteral nutrition with the pulmonary parenchyma (8). Several test methods were studied to verify the correct position of NG tube after it placement (9). For instance, the gastric auscultation of bubbles after an air injection across the NG tube is a technique used for verifying the correct position of the probe. The measurement of acidity with litmus paper or with a $\mathrm{pH}$ paper are also employed in order to confirm the adequate position of the NG tube. However, this tests not ensure the necessary degree of reliability in all cases. Moreover, is important to underline that the placement of a NG tube is technically more difficult in some patient. Specifically, patient with altered state of consciousness or patients presenting anatomical alterations of the upper aero-digestive path are more inclined to suffer a dislocation of the NG tube into the respiratory tract. In view of the above considerations, we consider that patient underwent major head and neck surgery should be considered high risk patients for NG tube placement. Against this background, we strongly believe that a chest $x$-ray should always be carried out after a NG tube placement in these cases. Obviously, rx control must be performed before before starting the enteral nutrition. This report raises four central points. First is the correlation between aspiration pneumonia and head and neck surgery. In fact, the surgical aggression of the upper aero-digestive path associated with the immunosuppressive state induced by surgery and the need of enteral nutrition for long time periods predispose patients to develop respiratory complications of NG tube. Second, in these patients a radiographic control for confirming the correct position of NG tube is mandatory. The anatomical alteration the upper gastrointestinal tract could interfere with the placement of the NG tube. Third, Research is urgently required on how to avoid tube misplacement. Respiratory complication caused by an incorrect position of NG tube may contribute to increase patient postoperative morbidity and mortality.

\section{REFERENCES}

1. S. Petrar, C. Bartlett, R.D. Hart, P. MacDougall. Pulmonary complications after major head and neck surgery: A retrospective cohort study. Laryngoscope. 2012; 122(5):105761. doi: $10.1002 /$ lary.23228.

2. D. Damian, J. Esquenazi, U. Duvvuri, J.T. Johnson, T. Sakai. Incidence, outcome, and risk factors for postoperative pulmonary complications in head and neck cancer surgery patients with free flap reconstructions.J Clin Anesth. 2016; 28:12-8. doi: 10.1016/j.jclinane.2015.08.007.

3. E. Cole. Improving the documentation of nasogastric tube insertion and adherence to local enteral nutrition guidelines. BMJ Quality Improvement Reports 2015. doi: 10.1136/ bmjquality.u203207.w1513.

4. T.M. Mekhail, D.J. Adelstein, L.A. Rybicki, M.A. Larto, J.P. Saxton, P. Lavertu. Enteral nutrition during the treatment of head and neck carcinoma: is a percutaneous endoscopic gastrostomy tube preferable to a nasogastric tube? Cancer. 2001; 91(9):1785-90.

5. C. Mahoney, A. Rowat, M. Macmillan, M. Dennis. Nasogastric feeding for stroke patients: practice and education. Br J Nurs. 2015; 24:319-20, 322-5. doi: 10.12968/bjon.2015.24.6.319.

6. J. C. Montejo González, B. Estébanez Montiel. Complicaciones gastrointestinales en el paciente crítico. Nutr Hosp. 2007; 22:56-62.

7. E.N. Andresen, M. Frydland, L. Usinger. Deadly pressure pneumothorax after withdrawal of misplaced feeding tube: a case report. Send to: J Med Case Rep. 2016; 10:30. doi: 10.1186/s13256-016-0813-y.

8. G.F. Gomes, J.C. Pisani, E.D. Macedo, A.C. Campos. The nasogastric feeding tube as a risk factor for aspiration and aspiration pneumonia. Curr Opin Clin Nutr Metab Care. 2003; 6:327-33

9. S. Taylor, K. Allan, H. McWilliam, A. Manara, J. Brown, D. Toher, W. Rayner. Confirming nasogastric tube position with electromagnetic tracking versus $\mathrm{pH}$ or $\mathrm{X}$-ray and tube radioopacity. Br J Nurs. 2014; 23:352, 354-8. 